\title{
Alimentando a su Bebé ${ }^{1}$
}

\author{
Linda B. Bobroff ${ }^{2}$
}

La alimentación de su bebé es uno de los primeros actos que usted realiza como padre. También es una de las maneras de iniciar su relación con el nuevo miembro de la familia. Cuando no hay problemas con la alimentación de su bebé, todos en la familia son más felices.

La información que le presentamos aquí puede ayudarle a desarrollar una buena relación de alimentación con su bebé. Las técnicas que va a aprender también le ayudarán a usted y a su niño a evitar conflictos que suelen presentarse durante la niñez y la edad preescolar.

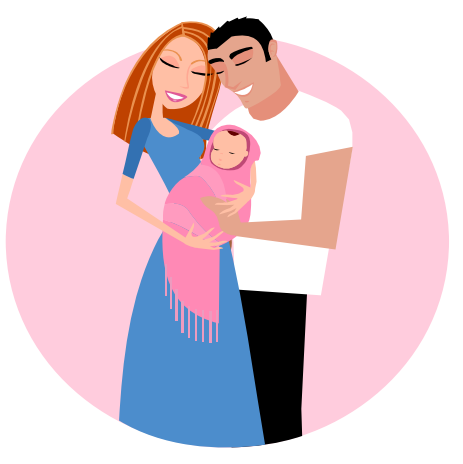

\section{Acercarse a su Bebé}

La relación con su bebé empieza justo después del nacimiento. Usted se comunica

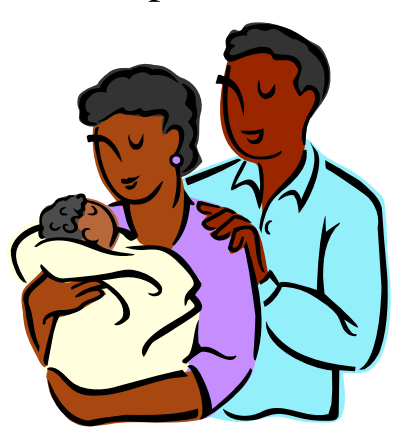
con su bebé cuando lo aguanta en sus brazos mientras le alimenta con leche materna o formula infantil. Los padres y cuidadores demuestran su amor por sus bebés cuando aprenden lo que significan los diferentes llantos y atienden a las necesidades de sus bebés. Nunca podrá mal criar a su bebé por simplemente atender y sostenerlo cuando llore.
Una manera importante de comunicar el amor que usted siente por su bebe es mediante la alimentación. Dar de comer a sus bebés cuando estos lo piden, es una manera de hacerlos sentir amados y seguros.

\section{Compartir Responsabilidades}

¿Ha pensado alguna vez en compartir la responsabilidad de la alimentación de su bebé con el? Puede que suene extraño pero los dos tienen un papel importante en la alimentación de su bebé. Veamos a continuación las funciones que deben realizar usted y su bebé para que así usted pueda concentrarse en su papel.

1. The English version of this Spanish document is Feeding Your Baby (FCS8545). This document was formerly known as FCS8548. Este documento, FCS8545-SPAN, pertenece a una serie del Departamento de Ciencias de la Familia, Juventud y Comunidad, Servicio de Extensión Cooperativo de la Florida, Instituto de Alimentos y Ciencias Agrícolas, Universidad de la Florida. Fecha de publicación: enero 1998. Revisado: octubre 2006. Favor de visitar el EDIS Web site en el http://edis.ifas.ufl.edu

2. Linda B. Bobroff, profesora, Departamento de Ciencias de la Familia, Juventud y Comunidad, Servicio de Extensión Cooperativo de la Florida, Instituto de Alimentos y Ciencias Agrícolas, Universidad de la Florida. Traducción por Sergio Romero anteriormente con la Universidad de la Florida, Gainesville, 32611. 


\section{El Papel de los Padres}

¿Cuál es su papel en la alimentación de su bebé? Dicho simplemente, usted debe ofrecer alimentos sanos que sean apropiados para la edad de su hijo y hacer esto de manera amable y cariñosa.

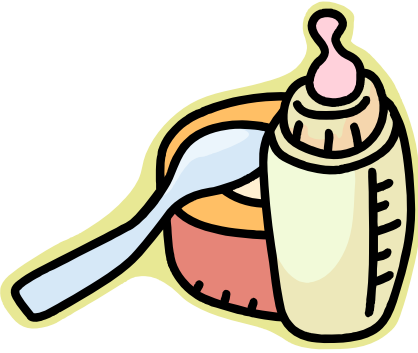

Note que la palabra que usamos es ofrecer, no obligar a que coma. Simplemente ofrezca alimentos nutritivos y fáciles de comer y deje que sea el bebé el que decida. Los bebés de menos de 4 a 6 meses de edad solo necesitan leche materna o formula infantil fortificada con hierro, así que a esta edad su trabajo es muy sencillo. Cuando crea que su bebé tiene hambre, ofrézcale el pecho o la botella y vea como reacciona. Un bebé hambriento no tardará en dirigirse al pecho para empezar a lactar o hacia la botella para hacer lo mismo.

\section{El Papel del Bebé}

¿Cual es el papel del bebé en su alimentación? Dé a su bebé la oportunidad de decidir cuanto va a comer e incluso si va a comer o no. Después de todo, ¿quién sabe mejor si el bebé tiene hambre? Por supuesto, el propio bebé.

Los bebés también saben cuando han comido lo suficiente y quieren parar de comer. Si prestamos atención, podemos responder a sus señales y parar de dar de comer cuando veamos que el bebé no quiere más. Incluso cuando queda algo de formula en la botella, pare de darle de comer cuando el bebé muestre que ha terminado.
Cuando dejamos que el bebé decida nuestra labor es muy sencilla. Cuando el bebé llora de hambre, es el mejor momento de darle de comer. Cuando el bebé voltea la cabeza y parece desinteresado, es el momento de parar. No hay necesidad de preocuparse, su bebé le dejará saber cuando es tiempo de comer de nuevo.

Dar de comer a su bebé de esta manera puede resultar un poco pesado, pero sepa que esto no va a durar mucho. Este tipo de alimentación solo debe de durar un año. Cuando su bebé crezca usted tendrá la oportunidad de planear sus comidas. En el primer año déjese guiar por las señales de hambre de su bebé.

\section{El Mejor Comienzo para su Bebé}

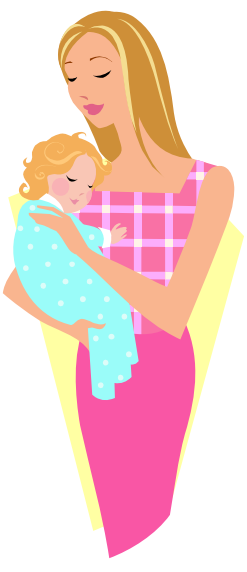

La primera comida de su bebé es la leche maternal o formula infantil fortificada con hierro. Cualquiera de estos dos alimentos provee los nutrientes necesarios para su bebé. La leche materna es el alimento perfecto para su bebé porque está hecha especialmente para el.

Algunas de las ventajas de la leche materna son:

(:) Tiene la composición de nutrientes adecuada para su bebé.

(): Es fácil de digerir.

(): Contiene factores inmunológicos.

(;) No cuesta nada.

(;) Es conveniente. 
(;) Puede ayudar a la madre a perder peso.

(:) Permite una unión intima entre la madre y el bebé.

La formula infantil puede ser una buena idea para algunas familias. Todos los miembros de la familia pueden ayudar a alimentar al bebé (aunque existen métodos para succionar la leche materna que también se puede almacenar para ser usada más tarde). Algunas madres se pueden sentir menos atadas cuando usan formula infantil. Si la dieta de la madre no es adecuada o si la madre usa drogas o bebe alcohol, se recomienda el uso de formula infantil en lugar de leche materna.

Asegúrese de usar formula especialmente producida para bebés. No use leche evaporada o leche de soja. Las formulas infantiles en polvo son más baratas que las que vienen listas para consumir. Siga cuidadosamente las instrucciones del fabricante.

Para ayudar a desarrollar el contacto intimo que se produce cuando la madre amamanta a su hijo, considere los siguientes consejos:

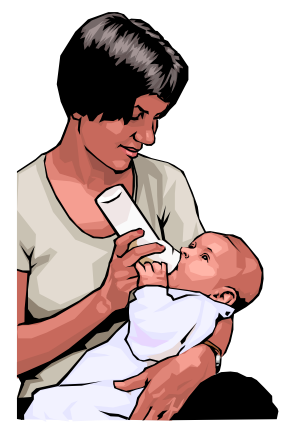

(:) Agarre a su bebé con seguridad pero sin apretar demasiado.

(:) Mire a su bebé y sonría.

suavidad.
-) Termine la comida del bebé cuando este voltee la cabeza hacia el otro lado, llore o se muestre inquieto en sus brazos.

Sáquele el aire al bebé con delicadeza.

(:) Ofrézcale la botella de nuevo después de calmar y sacarle el aire a su bebé. Deje que el bebé decida si quiere comer más o no.

(:) NO deje a su bebé solo con la botella puesta en la boca. Los bebés necesitan sentir el contacto de la persona mientras comen para sentirse seguros.

(:) Nunca ponga en la botella algo que no sea formula infantil, leche maternal o agua.

Tanto si da el pecho a su bebé o usa formula infantil, usted puede desarrollar una relación intima con su bebé siguiendo las recomendaciones que le hemos ofrecido.

Recuerde que los tiempos difíciles no duran demasiado; aunque tampoco lo hacen los buenos momentos. Así que recuerde, disfrute de cada minuto que pase con su bebé, porque antes de que se de cuenta ya habrá crecido.

Para más información sobre la alimentación de los recién nacidos, contacte a una de las siguientes agencias en su condado:

- Educador de Ciencias de Familia y Consumidor de Extensión Cooperativo (Busque en las páginas azules de su libreto telefónico). En la 
siguiente página web se encuentra un listado de las oficinas de Extensión de la Florida:

http://www.ifas.ufl.edu/extension/ces map.htm

- Dietista del programa WIC en el Departamento de Salud (También en las páginas azules de su libreto telefónico).

- Para referirse a una dietista registrada (RD) en su área llame a la Florida Dietetic Association al 850/386-8850 o busque en las páginas amarillas de su libreto telefónico.

\section{Lecturas Recomendadas (en Inglés)}

Satter, E. (2000.) Child of Mine: Feeding with Love and Good Sense. (3rd ed.) Palo Alto: Bull Publishing Company. ISBN: 0-92352-151-8

Satter, E. (1987). How to Get Your Kid to Eat...But Not Too Much. Boulder: Bull Publishing Company. ISBN: 0-915950-83-9

\section{Páginas Web recomendadas (en inglés)}

Food and Nutrition Information Center, National Agricultural Library, USDA. Información sobre nutrición y salud de los niños. Consulte la página web:

http://www.nal.usda.gov/fnic/etext/000008.html

American Dietetic Association. Feeding Infants and Toddlers Under Two Years. (1996) En la página web:

http://www.eatright.org/cps/rde/xchg/ada/hs.xsl/nutrition_5432_ENU_HTML.htm 